\title{
Granulometric characterization of airborne particulate release during spray application of nanoparticle-doped coatings
}

\author{
Daniel Göhler • Michael Stintz
}

Received: 7 March 2014/ Accepted: 14 June 2014/Published online: 4 July 2014

(C) The Author(s) 2014. This article is published with open access at Springerlink.com

\begin{abstract}
Airborne particle release during the spray application of coatings was analyzed in the nanometre and micrometre size range. In order to represent realistic conditions of domestic and handcraft use, the spray application was performed using two types of commercial propellant spray cans and a manual gravity spray gun. Four different types of coatings doped with three kinds of metal-oxide tracer nanoparticle additives (TNPA) were analyzed. Depending on the used coating and the kind of spray unit, particulate release numbers between $5 \times 10^{8}$ and $3 \times 10^{10}$ particles per gram ejection mass were determined in the dried spray aerosols. The nanoparticulate fraction amounted values between 10 and 60 no\%. The comparison between nanoparticle-doped coatings with non-doped ones showed no TNPA-attributed differences in both the macroscopic spray process characteristics and the particle release numbers. SEM, TEM and EDX-analyzes showed that the spray aerosols were composed of particles made up solely from matrix material and sheathed pigments, fillers and TNPAs. Isolated $\mathrm{ZnO}-$ or $\mathrm{Fe}_{2} \mathrm{O}_{3}$-TNPAs could not be observed.
\end{abstract}

D. Göhler $(\bowtie) \cdot$ M. Stintz

Research Group Mechanical Process Engineering, Institute of Process Engineering and Environmental Technology, Technische Universität Dresden, Münchner Platz 3, 01062 Dresden, Germany

e-mail: daniel.goehler@tu-dresden.de
Keywords Nanoparticle release - Airborne particle emission - Spray application - Spray can - Spray gun . Nanoparticle-doped coatings $\cdot$ Risk assessment

\section{Introduction}

Nanomaterials are affected by the evolving risk discussions between stakeholders in research, governments, regulators, non-governmental organizations and industry, but currently no harmonized definition of the term nanomaterial exists under regulatory aspects.

A science-based terminology for nanomaterials is given in ISO/TS 80004-1:2010, wherein a distinction is drawn between nano-objects and nanostructured materials. The identifying feature of nanostructured materials is their internal or surface structure in the nanoscale $(\leq 100 \mathrm{~nm})$, but their external dimensions are typically greater. Beside the ISO terminology, the European Commission issued a recommendation on the definition of nanomaterials (2011/696/EU) (European Commission 2011). This definition comprises "natural, incidental or manufactured materials containing particles in an unbound state or as an aggregate or as an agglomerate and where, for $50 \%$ or more of the particles in the number size distribution, one or more external dimension is in the size range 1-100 nm". Consequently, the EC-definition based solely on the size of the constituent particles of the 
material, without regard to material properties or to hazard and risk.

The coating industry processes numerous materials within their products (e.g. dispersing agents, pigments, fillers), which are covered by both the recommendation of the European Commission and ISO/TS 80004-1:2010. In this context, a particulate risk assessment is reasonable for this sector of industry.

Besides the hazard profile of a substance, the second fundamental premise to perform an overall risk assessment is the exposure (e.g. NRC 1983). Kuhlbusch et al. (2011) reviewed published studies on exposure characterization by workplace measurement and laboratory analyses and concluded that the latter ones can provide basic information about the ability and the quantity of airborne nanoparticle release. In this context, a recently published review (Froggett et al. 2014) pointed out that only the half of the 54 available release studies for solid nanocomposites have an experimental nature, whereas the others ones have a more observational character. Froggett et al. (2014) concluded that future work should spend more attention on the release processes itself. Nevertheless, Brouwer (2010) showed that several potential release scenarios for engineered nano-objects (ENO) exist in the whole nanomaterial life-cycle for the coating industry. The comparison of identified release scenarios (e.g. Brouwer 2010) with available release studies (e.g. Kuhlbusch et al. 2011) showed that until now only little attention was spent on the spray application of coatings.

In 2012, a total number of more than 5.5 billion spray cans were produced in Europe. Around 200 million cans of them were filled with coatings, whereof about 75 million were made in Germany (FEA European Aerosol Federation 2013). Losert et al. (2014) reviewed the few studies regarding the release of nano-objects from spray products, which were performed without exception by chamber and room experiments. For example, Hagendorfer et al. (2010) have analyzed the nanometre size range of spray aerosols that originated from aqueous silvernanoparticle suspensions, which were aerosolized by propellant and pump spray cans within a test chamber. Aside from these, some published studies exist, which deal with the analysis of coating spray aerosols in the size range above $300 \mathrm{~nm}$ (e.g. Brosseau et al. 1992; Carlton and Flynn 1997; Sabty-Daily et al. 2005).

The aim of the present study was to fill this gap by granulometric characterization of coating spray aerosols originating from two types of commercial propellant spray cans and a manual gravity spray gun. In order to solve the complex metrological challenge, orientation measurements were performed firstly in an industrial spray booth. The gathered data regarding the magnitude of particle number concentrations and particle sizes will not discussed here but served for the design of a laboratory spray-channel and for a suitable experimental setup. In a second step, the spray processes were macroscopically characterized before the actual (nano)particle release analyzes were performed. The (nano)particle release characterization was carried out according to the approach used in Göhler et al. (2010) and which is described more detailed in Göhler et al. (2013).

\section{Materials and methods}

Spray application units

Three different coating spray-application technologies in the field of domestic use and handcraft were analyzed in this study, i.e. standard spray cans (SSC), SprayMax ${ }^{\circledR}$-cans (SMC) and a manual gravity spray gun (SGA).

SSCs, which based on propellant gas and circularstream-atomization, are typically operated in domestic use. Spray cans based on the SprayMax ${ }^{\circledR}$-technology (patent specification DE9636221 and US5957341) are used in the area of handcraft. They have a higher ejection mass flow than SSCs due to higher inner propellant pressure. Additionally, SMCs are typically operated with broad-stream atomization.

Pressurized air spray guns are more common used in the area of handcraft as SMCs. For the spray gun application (SGA), a high volume low pressure (HVLP) manual gravity spray gun (Model W300 08 G200, Anest Iwata Corporation, Japan) with a $0.8 \mathrm{~mm}$ nozzle was operated at 2.5 bar system pressure in circular-stream-mode.

\section{Materials}

Coatings and tracer nanoparticle additives (TNPA)

The four coating systems, which were analyzed in this study, are given in Table 1. The first two coating systems (PU, ACL) are typically used in the domestic 
Table 1 Coating systems, analyzed spray processes and sample identification key

\begin{tabular}{|c|c|c|c|c|c|}
\hline Coating system & TNPA & SSC & SMC & SGA & $\begin{array}{l}\text { Sample } \\
\text { ID }\end{array}$ \\
\hline \multirow{3}{*}{$\begin{array}{l}\text { Two-pack } \\
\text { polyurethane } \\
\text { coating }\end{array}$} & - & $\mathrm{x}$ & $\mathrm{x}$ & & PU \\
\hline & $\mathrm{ZnO}^{\mathrm{a}}$ & $\mathrm{x}$ & $\mathrm{x}$ & & PU-ZnO \\
\hline & $\mathrm{Fe}_{2} \mathrm{O}_{3}^{\mathrm{b}}$ & $\mathrm{x}$ & $\mathrm{x}$ & & $\mathrm{PU}-\mathrm{Fe}_{2} \mathrm{O}_{3}$ \\
\hline \multirow{3}{*}{$\begin{array}{l}\text { Acrylate topcoat } \\
\text { with } \mathrm{TiO}_{2} \\
\text { pigment } \\
\text { particles }\end{array}$} & - & $\mathrm{x}$ & $\mathrm{x}$ & & ACL \\
\hline & $\mathrm{ZnO}^{\mathrm{a}}$ & $\mathrm{x}$ & $\mathrm{x}$ & & $\mathrm{ACL}-\mathrm{ZnO}$ \\
\hline & $\mathrm{Fe}_{2} \mathrm{O}_{3}^{\mathrm{b}}$ & $\mathrm{x}$ & $\mathrm{x}$ & & $\mathrm{ACL}-\mathrm{Fe}_{2} \mathrm{O}_{3}$ \\
\hline \multirow{2}{*}{$\begin{array}{l}\text { Water-based } \\
\text { coating with } \\
\mathrm{TiO}_{2} \text { pigment } \\
\text { particles }\end{array}$} & - & $\mathrm{x}$ & $\mathrm{x}$ & $\mathrm{x}$ & WL \\
\hline & $\mathrm{SiO}_{2}^{\mathrm{c}}$ & $\mathrm{x}$ & $\mathrm{x}$ & $\mathrm{x}$ & $\mathrm{WL}-\mathrm{SiO}_{2}$ \\
\hline \multirow{2}{*}{$\begin{array}{l}\text { Organic } \\
\text { solvent-based } \\
\text { mixed coating }\end{array}$} & - & $\mathrm{x}$ & $\mathrm{x}$ & $\mathrm{x}$ & LML \\
\hline & $\mathrm{SiO}_{2}^{\mathrm{c}}$ & $\mathrm{x}$ & $\mathrm{x}$ & $\mathrm{x}$ & $\mathrm{LML}-\mathrm{SiO}_{2}$ \\
\hline \multicolumn{6}{|c|}{ a Formulation LP-X 21217} \\
\hline \multicolumn{6}{|c|}{${ }^{\mathrm{b}}$ Formulation JS-08-032A } \\
\hline \multicolumn{6}{|c|}{ c Hydrophobized synthetic amorphous silica } \\
\hline
\end{tabular}

field, whereas the last two ones (WL, LML) are applied in the area of handcraft and industry.

Three different kinds of metal-oxide tracer nanoparticle additives (TNPA) were deliberately admixed to the coating systems. The employed $\mathrm{ZnO}-$ and $\mathrm{Fe}_{2} \mathrm{O}_{3}$-TNPAs were the same ones as used in previous studies (Vorbau et al. 2009; Göhler et al. 2010). The $\mathrm{ZnO}-\mathrm{TNPA}$ with a number weighted median diameter of $x_{50,0, \mathrm{ZnO}}=75 \mathrm{~nm}$ and a nanoparticulate fraction of $Q_{0, \mathrm{ZnO}}(100 \mathrm{~nm})=75$ no $\%$ are finer but broader distributed than the $\mathrm{Fe}_{2} \mathrm{O}_{3}$-TNPA with a median diameter of $x_{50,0, \mathrm{Fe}_{2} \mathrm{O}_{3}}=115 \mathrm{~nm}$ and a nanoparticulate fraction of $Q_{0, \mathrm{Fe}_{2} \mathrm{O}_{3}}(100 \mathrm{~nm})=25 \mathrm{no} \%$. The TNPA SiO $\mathrm{S}_{2}$ is an hydrophobized synthetic amorphous silica (SAS) that consists of fractal aggregates of sintered primary particles with an average primary particle diameter of $7 \mathrm{~nm}$. The BET surface area is specified by the manufacturer with $220 \pm 25 \mathrm{~m}^{2} \mathrm{~g}^{-1}$.

Chemical composition within the spray units

The rough chemical composition of the analyzed coatings within the different spray units is given in Fig. 1 and can be classified in three main categories, i.e. propellant $(\mathrm{P})$, solvent $(\mathrm{S})$ and solid matter $(\mathrm{M})$.

The propellant-content of dimethyl ether $\left(\mathrm{C}_{2} \mathrm{H}_{6} \mathrm{O}\right)$ or of mixtures of butane $\left(\mathrm{C}_{4} \mathrm{H}_{10}\right)$ and propane $\left(\mathrm{C}_{3} \mathrm{H}_{8}\right)$ within the spray cans reached from 34 to $46 \mathrm{wt} \%$. In contrast to the spray cans, the mass content of the spray gun propellant gas (particle free pressurized air) is not specified due to the possibility of different spray gun operating conditions.

The solvent-content comprises beside organic solvents and diluents also the content of water in the case of water-based coatings. Within the spray cans, the waterbased coating solvent-content amounted $27 \mathrm{wt} \%$, whereas the other coatings contained $42 \mathrm{wt} \%$ up to $52 \mathrm{wt} \%$ of solvent. Due to the lack of propellant specification, the solvent-content for the spray gun coatings is therefore higher and amounts to $44 \mathrm{wt} \%$ for the water-based coatings and to $75 \mathrm{wt} \%$ for the organicsolvent-based coatings.

The third category comprises the non-volatile components. Except the pigment-content and TNPAcontent, all other solid components (e.g. binder, hardener, filler, dispersing agents) were summarized in the subcategory matrix. Considering the spray cans, the non-volatile content amounts $27 \mathrm{wt} \%$ for the water-based coatings and varied for the other coatings between 11 and $17 \mathrm{wt} \%$. In the case of SGA, the solid content of the organic-solvent coatings amounts 56 and $25 \mathrm{wt} \%$ for the water-based coatings.

The TNPA content varies in the case of the spray cans (SSC, SMC) between 0.2 and $1.2 \mathrm{wt} \%$, whereas it ranges from 0.7 to $2.6 \mathrm{wt} \%$ for SGA. Considering solely the non-volatile components (i.e. the final surface coating after application and drying), the content of the TNPAs $\mathrm{ZnO}$ and $\mathrm{Fe}_{2} \mathrm{O}_{3}$ would amount to values of 1.3-2.0 wt $\%$ and the $\mathrm{SiO}_{2}$-TNPA content would be $1.2 \mathrm{wt} \%$ for the WL-coating or $10.3 \mathrm{wt} \%$ for the LML-coating.

\section{Experimental details}

Spray-channel

Due to the multitude of aerosol-analytical disadvantages (e.g. relatively high setup times, fluidic dead zones, different residence times, poor mixing, concentration gradients) accompanied with the use of test chambers, a simple spray-channel (see Fig. 2) made from standardized polypropylene components (EN 1451-1:1999) was developed for the spray aerosol characterization. The main parts of the $1635 \mathrm{~mm}$ long spray-channel are an air supply section, a spray module with spray chamber for the inclusion of the 


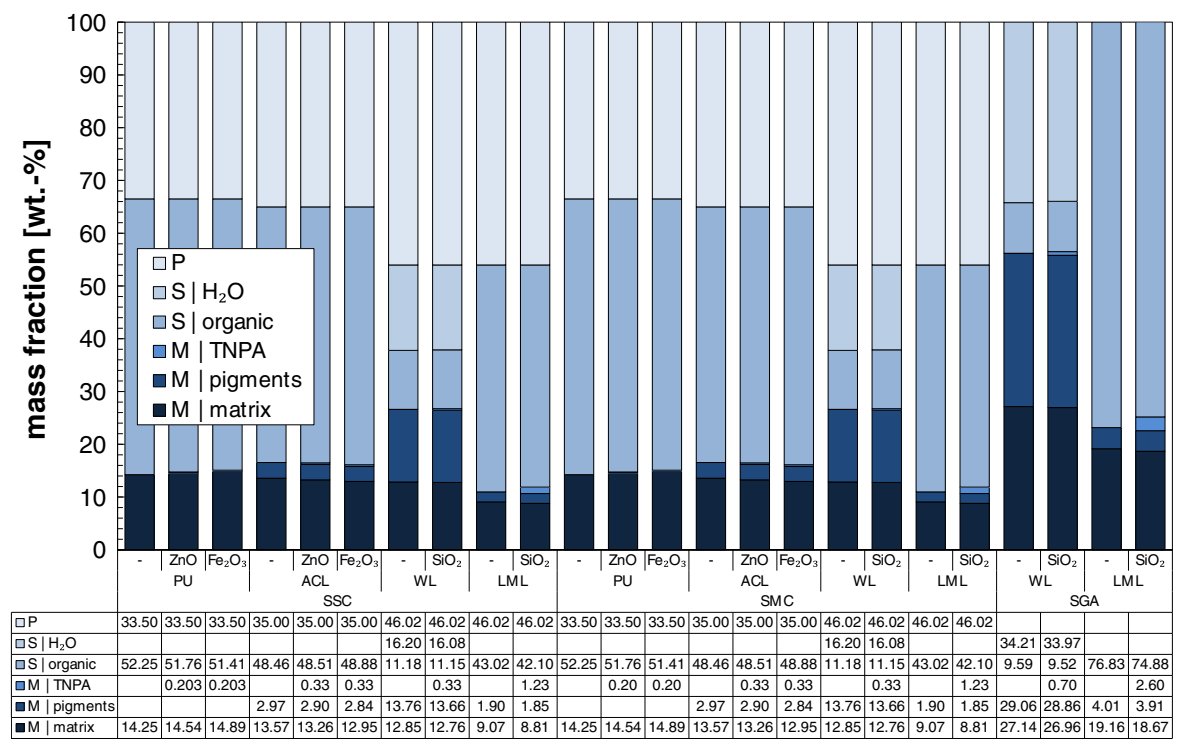

Fig. 1 Chemical composition of the analyzed coatings as configured within the operated spray units

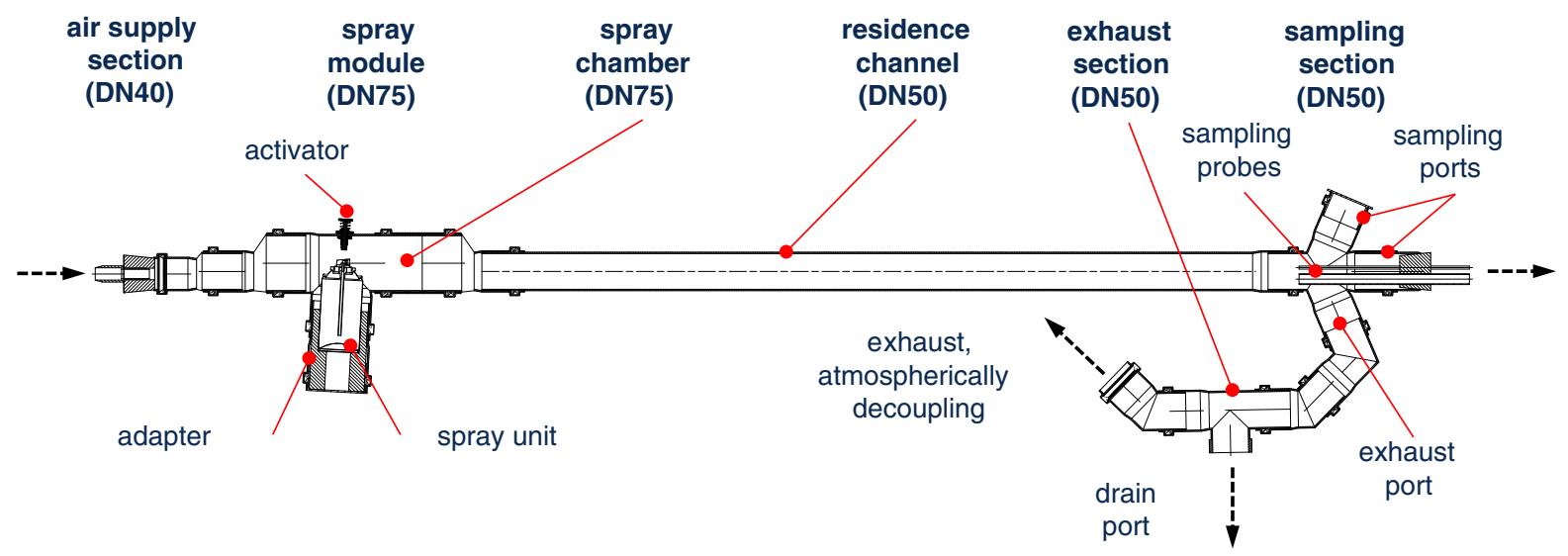

Fig. 2 Sectional view of the developed spray-channel for aerosol characterization of spray cans and spray guns

spray units, a residence channel, a sampling and an exhaust section.

Within the spray-channel, the spray aerosol generated in the spray module is immediately gathered by the supplied particle free volumetric air flow and fed through the residence channel to the atmospheric decoupled exhaust access. The supplied turbulent volumetric air flow serves also for spray aerosol predrying, particulate pre-dilution, pre-reduction of volatile organic components (VOC, based on propellant and organic solvents) and for providing a homogeneously distributed particle concentration over the channel cross section. The distance between the nozzle outlet of the spray units and the entrance to the sampling tubes of the sampling section was set to $1,235 \mathrm{~mm}$.

The spray module shown in Fig. 2 is the one used for the spray cans. Different adapter-designs allow the inclusion of various spray can geometries (e.g. nominal volume of $150,250,400 \mathrm{~mL}$ ). In the case of SGA, a similar spray-module was used, wherein the spray gun was positioned and protruding components were thread through sealed hollows as shown in the schematic diagram of the experimental setup in Fig. 3. 
Instrumentation

The target granulometric measurands for the spray aerosol characterization down to a few nanometres are the number weighted particle size distribution $\left(\mathrm{PSD}_{0}\right)$, the particle number concentration (PNC) and the elementary composition of the released particles. Currently, these measurands cannot be determined by a single measurement device. Therefore, different instruments were selected and combined in this study to obtain a general view of the particulate spray emissions.

An Engine Exhaust Particle Sizer (EEPS, Model 3090, TSI Inc., Shoreview, USA), a fast electrical mobility aerosol spectrometer (e.g. Biskos et al. 2005), was used for the temporally high-resoluted determination $(10 \mathrm{~Hz})$ of $\mathrm{PSD}_{0} \mathrm{~s}$ from $5.6 \mathrm{~nm}$ up to $560 \mathrm{~nm}$. The $\mathrm{PSD}_{0}$ of coarser spray aerosol particles in a range between $0.5-20 \mu \mathrm{m}$ was measured by an Aerodynamic Particle Sizer (APS, Model 3321, TSI Inc., Shoreview, USA), a time-of-flight optical particle counter (e.g. Wilson and Liu 1980). EEPS and APS determine both $\mathrm{PGV}_{0}$ and PNC. For the purpose of redundancy verifying, a condensation particle counter (CPC, Model 3022A, TSI Inc., Shoreview, USA), which bases on magnifying aerosol particles to an optical-detectable size by heterogeneous condensation (e.g. McMurry 2000), was used for the highly-sensitive detection of PNCs in a size range from 6 to $<10 \mu \mathrm{m}$. Imaging analyzes by scanning- (SEM) and transmission electron microscopy (TEM) and elementary analyses by energy dispersive X-ray spectroscopy (EDX) were performed on spray aerosol particles, which were deposited on substrates within an electrostatic precipitator (ESP; Dixkens and Fissan 1999).

In addition to the aerosol measurement instruments, different devices and procedures were necessary to achieve best possible measuring conditions. Thus, two different kinds of dilution systems were operated. A dynamic dilution system (Model DDS 560, ToPAS $\mathrm{GmbH}$, Dresden, Germany) based on bypass-filtration was operated solely for a defined reduction of the PNC. External air dilution units (Model VKL 10, Palas $\mathrm{GmbH}$, Karlsruhe, Germany) were used for a defined reduction of PNC and VOC (Koch et al. 1988; Helsper et al. 1990). For the purpose of aerosol neutralization, radioactive $\mathrm{Kr}^{85}$ bipolar neutralizers (Model 3077, TSI Inc., Shoreview, USA) were employed.
Experimental setup

Figure 3 shows the schematic diagram of the experimental setup that was operated for the particle release characterization during SGA. In the case of the spray cans, the same experimental setup was used but except the components for spray gun operation. The spraychannel was continuously purged by a defined volumetric flow between $200-300 \mathrm{~L} \mathrm{~min}^{-1}$ of HEPAfiltered air for spray aerosol transportation, drying and pre-dilution of PNC and VOC.

The extraction of the aerosol sample flow was realized by one respectively two VKLs, which were operated with dry $(<10 \% \mathrm{RH})$ and HEPA-filtered compressed air at a system pressure of 2.5 bar. Beside a defined particulate reduction, these dilution units allowed also a concentration decrease of VOC that was essential for occupational and instrumental safety.

Before entering the flow splitter, the aerosol was passed through a cascade of two bipolar neutralizers. Both the EEPS and the ESP got their aerosol sample without further dilution procedures, whereas the sample flow for the CPC and the APS was fed firstly in a DDS. The sample flow of the APS was additionally diluted by partial backmixing with HEPA-filtered device exhaust.

For the operation of the experimental setup, nonconductive tubing was installed before the neutralizers, whereas conductive tubing was used after the neutralizers.

\section{Experimental procedure}

The experimental procedure was carried out stepwise. Firstly, the spray units to be analyzed were activated, i.e. the mixture of the two-pack coatings were initiated for the spray cans respectively the gravity feed cup of the spray gun was filled. Afterward the spray units were gravimetrically analyzed using an analytical balance (Model BP310S, Sartorius AG, Göttingen, Germany). The spray cans (SSC, SMC) were then shaken manually not less than $30 \mathrm{~s}$ and further agitated by a laboratory shaker (Model IKA ${ }^{\circledR}$ MS3 digital, IKA $^{\circledR}$-Werke GmbH \& Co. KG, Staufen, Germany) for $60 \mathrm{~s}$ at an agitation stroke of $4.5 \mathrm{~mm}$ and a rotational frequency of $3,000 \mathrm{~min}^{-1}$.

After assembling with the spray units, the spraychannel was firstly purged for $10 \mathrm{~s}$ with particle-free air before the actual data logging for $60 \mathrm{~s}$ began. The 


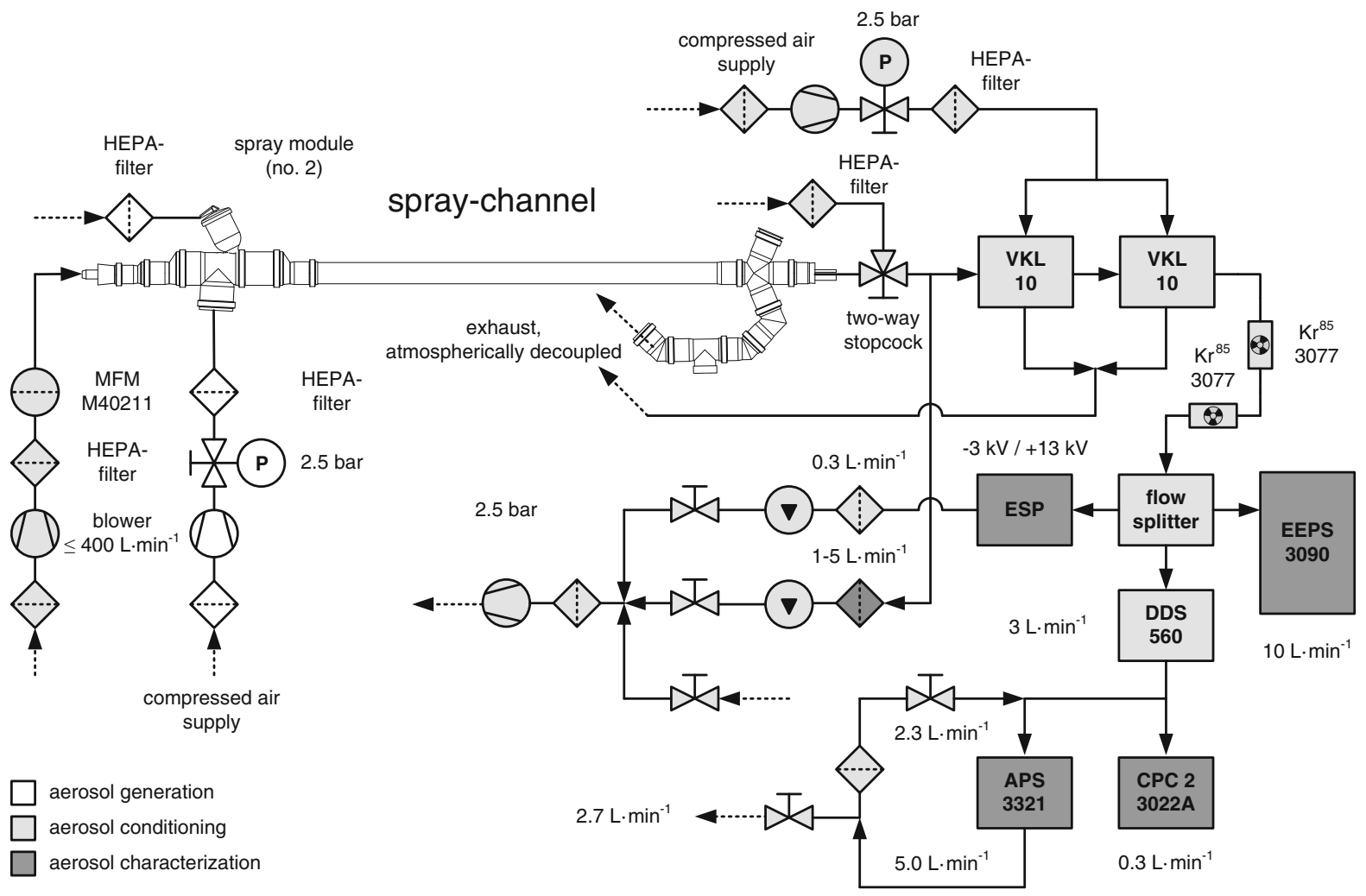

Fig. 3 Schematic diagram of the experimental setup for spray application, aerosol conditioning and characterization

first $10 \mathrm{~s}$ of the measurement period were performed without any action to receive data for the offsetcorrection of the inherent EEPS electrometer noise. This was followed by the actual spraying process that lasted for $5 \mathrm{~s}$. During the remaining measurement time, no further interventions were performed. The described measurement procedure led to a characteristic progression in the measurement data as exemplarily shown for the EEPS-data in Fig. 4.

Subsequently, the spray units were removed from the spray-channel and again gravimetrically analyzed. The whole experimental procedure was performed five times for each analyzed coating in the case of SGA. For the spray can application (SSC and SMC), a total of 6-12 single measurements were carried out using 2-4 single cans for each coating configuration.

After the completion of a measurement series for a coating configuration, the substrates for SEM-, TEMand EDX-analyses were removed from the ESP and immediately stored in airtight sample containers, which were decontaminated afore within a laminar flow bench (Modell LF-VM-K0615; Steag
Laminarflow Prozesstechnik GmbH, Pliezhausen, Germany) by purging with HEPA-filtered pressurized air. The substrate removal lasted approximately $3 \mathrm{~s}$, where each substrate was exposed to the laboratory atmosphere. To minimize potential contaminations, the laminar flow bench next to the experimental setup was operated the whole time during the measurement campaign. Prior the next measurement series, the spray-channel and the complete tubing were purified in order to avoid cross contaminations.

\section{Results and discussion}

Macroscopic spray process characterization

In order to determine quantitative release data, macroscopic ejection parameters of the spray units were examined before, during and after the release analyzes.

Figure 5a gives the ejection mass flows determined during the release analyses for a spray duration of $5 \mathrm{~s}$. The SMCs showed the highest ejection mass flows 


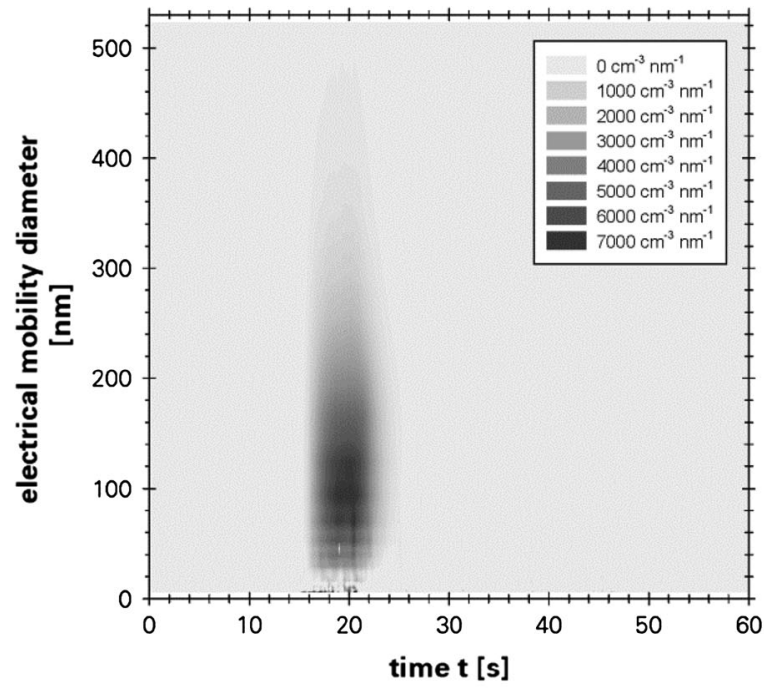

(a) SMC: $\mathrm{WL}_{-} \mathrm{SiO}_{2}($ no. 523)

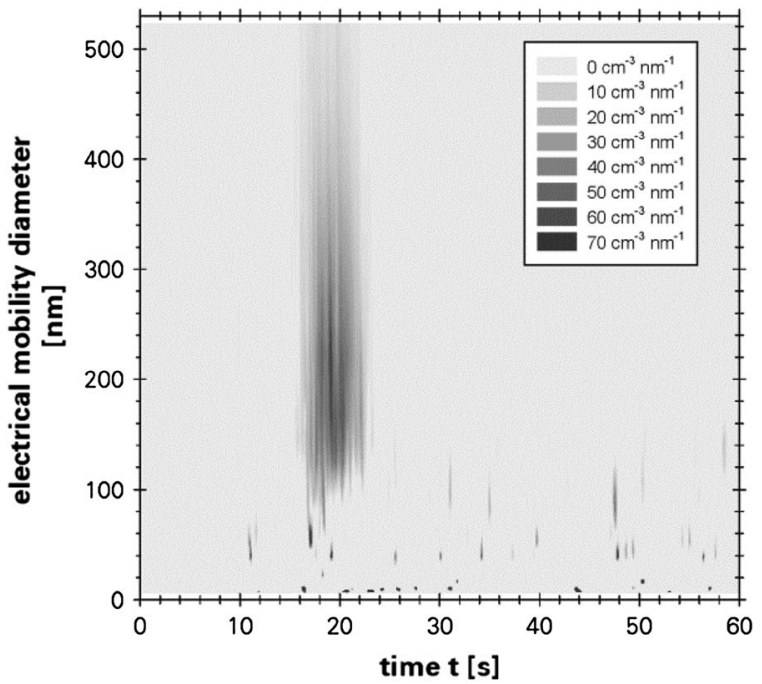

(b) SGA: WL-SiO 2 (no. 999)

Fig. 4 Visualization of the experimental procedure during EEPS data logging on the example of two single analyzes $\left(\mathrm{q}_{0} \cdot \mathrm{c}_{\mathrm{n}} \equiv \mathrm{dc} \mathrm{c}_{\mathrm{n}} / \mathrm{dx}\right)$; EEPS electrometer noise corrected

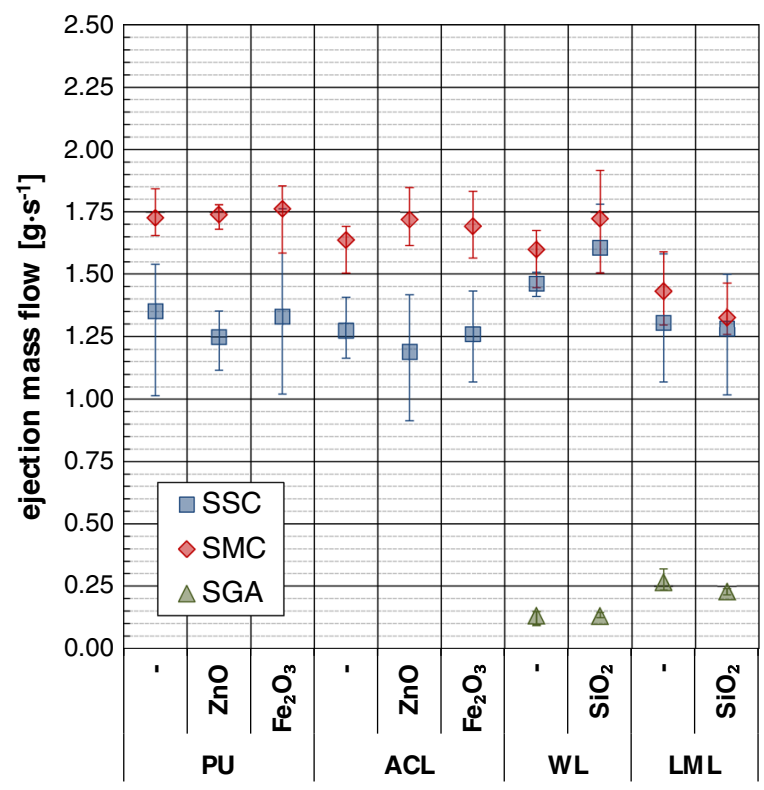

(a) ejection mass flow

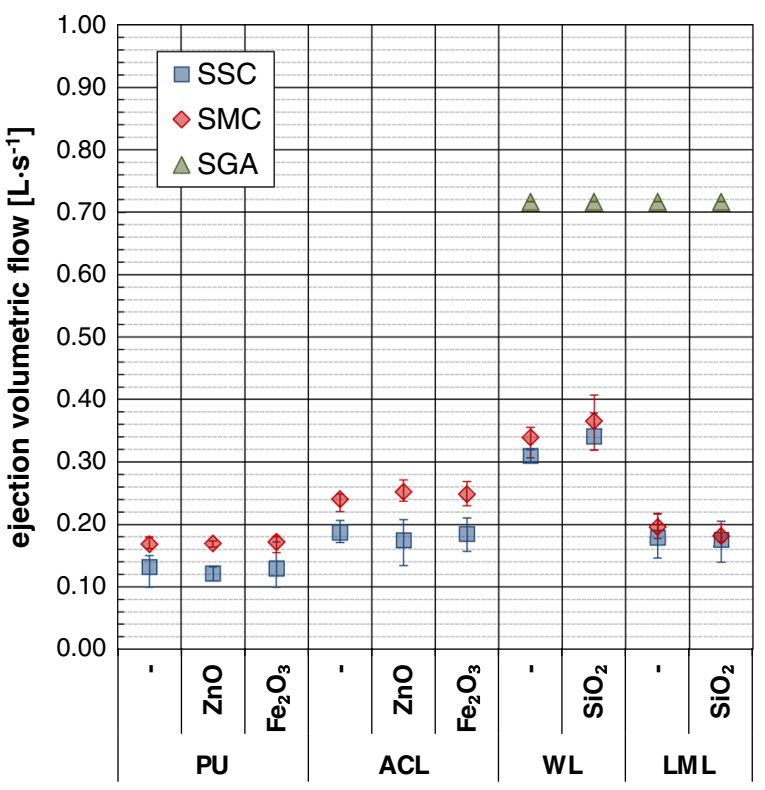

(b) ejection volumetric flow

Fig. 5 Ejection parameters of the spray cans (SSC, SMC) and the spray gun (SGA); error bars = data spreading of 5-12 single measurements

over all analyzed coating configurations, whereas the lowest ones resulted for SGA.

The determination of the ejection volumetric flows of the spray cans shown in Fig. $5 b$ based on gravimetrical identification of the displaced water mass that originated from the inflation of rubber bags. After correction by the bags surface tension and the acting water column, the ejection volume was related 
to simultaneous determined ejection masses. It was found that the ejection volume of the analyzed spray cans is directly proportional to the ejection mass irrespective of the spray can kind (i.e. SSC or SMC), the spray can dimension (i.e. 150,250 or $400 \mathrm{~mL}$ ) or the TNPA admixture. In contrast, it could be proved that the ratio of ejection volume and ejection mass depends on the containing coating system. The determined proportionality factors $\left(a_{\mathrm{PU}}=97.5\right.$ $\mathrm{mL} \mathrm{g}^{-1}, \quad a_{\mathrm{ACL}}=146.8 \mathrm{~mL} \mathrm{~g}^{-1}, \quad a_{\mathrm{WL}}=212.3-$ $\mathrm{mL} \mathrm{g}^{-1}, \quad a_{\mathrm{LML}}=136.9 \mathrm{~mL} \mathrm{~g}^{-1}$ ) were used in context with the determined ejection mass flows shown in Fig. 5a and led to the ejection volumetric flows of the spray cans as given in Fig. 5b. The ejection volumetric flow of the spray gun was characterized (system pressure 2.5 bar, operation without coating) by means of a mass flow meter (Model 40211, TSI Inc., Shoreview, USA).

Beside the ejection mass flow and the ejection volumetric flow, the volume-weighted droplet size distributions $\left(\mathrm{PSD}_{3}\right)$ of the spray units were determined in a distance of $10 \mathrm{~mm}$ to the spray nozzle outlet by means of a laser diffraction spectrometer (Model HELOS/KR-H2487, Sympatec GmbH, Clausthal-Zellerfeld, Germany) according to ISO 13320:2009. The HELOS was operated with a focal distance of $f_{\mathrm{R} 3}=100 \mathrm{~mm}$ to cover a size range between $0.9 \mu \mathrm{m}$ up to $175 \mu \mathrm{m}$. The determined density functions of the $\mathrm{PSD}_{3}$ contained the isolated target spray modus/peak of around $25 \mu \mathrm{m}$ and poorly-reproducible slopes in the density function at the upper and lower size range limits. The coarse droplets $(x>75 \mu \mathrm{m})$ have been visually observed before during the spray can analyzes, where they settled down in a distance between 10 and $50 \mathrm{~mm}$ from the spray nozzle exit. For the purpose of macroscopic droplet spray aerosol characterization, the target peaks were separated from the whole density function by a band-pass-filter algorithm. Afterward the characteristic parameters as shown in Fig. 6 of the target droplet peak were determined.

Regardless the kind of application unit, the volumeweighted median droplet diameter $\left(\mathrm{x}_{50,3}\right)$ of the analyzed coatings reached from 10 to $45 \mu \mathrm{m}$ as shown in Fig. 6a. The SPAs led to the finest (see Fig. 6 a) but broadest (see Fig. 6b) $\mathrm{PSD}_{3} \mathrm{~s}$ with $x_{50,3}=(10$ 20) $\mu \mathrm{m}$. The coarsest droplet aerosols with $x_{50,3}=$ (20-45) $\mu \mathrm{m}$ were determined for the SMCs, whereas the narrowest $\mathrm{PSD}_{3} \mathrm{~s}$ were detected for the SSCs. Comparing solely the two different kinds of spray cans, the droplet aerosols of the SSCs were in most cases finer than for the SMCs.

No significant impact on the droplet spray-aerosol characteristics could be attributed to the TNPAadmixture with $\mathrm{Fe}_{2} \mathrm{O}_{3}$ and $\mathrm{SiO}_{2}$. The observable significantly higher $x_{50,3}$-values of the $\mathrm{ZnO}$-doped coatings in comparison to their non-doped counterparts during SMC-application based less on the $\mathrm{ZnO}$ admixture but rather on the whole SMC-confection. The macroscopic results for the SSC-application and also the above-mentioned finding for the TNPAs $\mathrm{Fe}_{2} \mathrm{O}_{3}$ and $\mathrm{SiO}_{2}$ confirm this conclusion.

\section{Spray aerosol characterization}

Number-weighted particle size distributions $\left(\mathrm{PSD}_{0}\right)$

To visualize the size distribution and the relative amount of released particles over the whole measurement time, the PNC of each class (class index $k$ ) was accumulated over the time increments (time index $i$ ) of the measurement procedure, corrected by the used dilution factor $\varphi$ and related to the class width. This procedure was performed using the EEPS-data and logarithmic class width and led to the transformed and scaled number-weighted $\mathrm{PSD}_{0}$ of released particles as shown in Fig. 7.

The spray can aerosols (SSC, SMC) are very similar to one another for the particular coatings regarding the curve shape. In contrast, significant differences can be observed comparing the spray can aerosols and the spray gun aerosols, especially for the water-based coatings (see Fig. 4). Excepting the water-based coatings, all size distributions show a secondary peak around $10 \mathrm{~nm}$ and below, that could be originate from the formation of secondary organic aerosol (SOA) particles due to the high amount of VOC. The relaxation process could maybe caused a SOA formation. A formation initiated by the corona charger of the EEPS can be excluded, because despite the flow circuit within the EEPS no continuous SOA-peak could be observed.

Beside the curve shapes, the scaled size distributions of Fig. 7 allow also an estimation of the relative release amount under the premise of comparable process and analytical parameters. In contrast to the SGA, the ejection parameters (see Fig. 5) of SSC and 


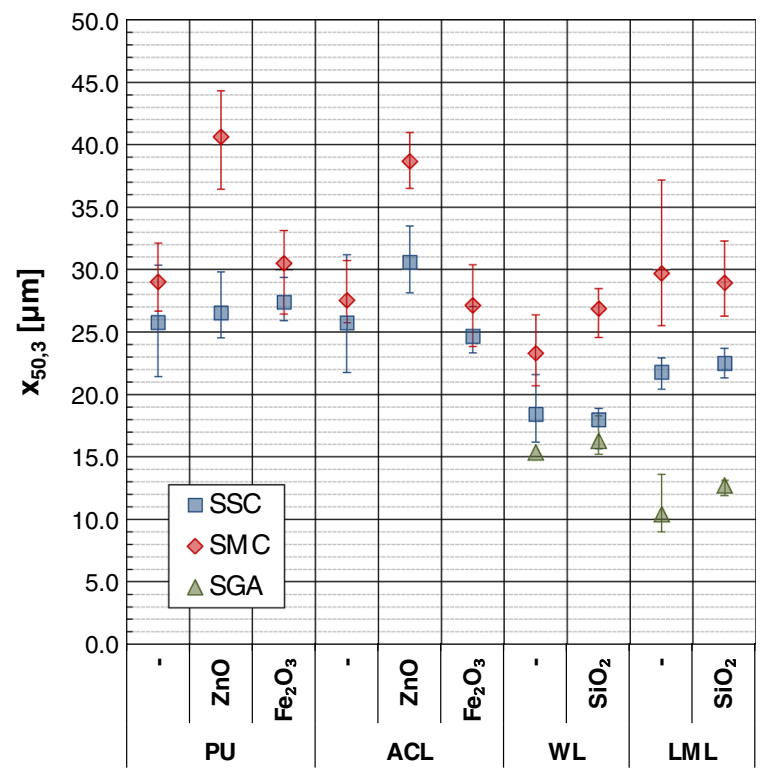

(a) median droplet size, $\mathrm{x}_{50,3}$

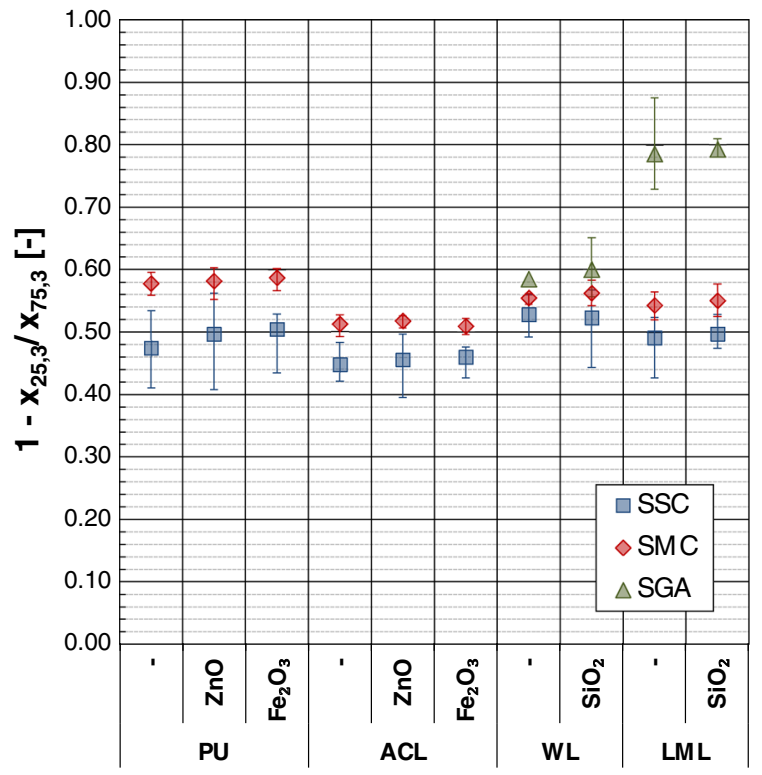

(b) distribution width, 1-( $\left.\mathrm{x}_{25,3} / \mathrm{x}_{75,3}\right)$

Fig. 6 Characteristic parameters of the volume-weighted droplet size distribution $\left(\mathrm{PSD}_{3}\right)$ at a distance of $10 \mathrm{~mm}$ from the nozzle exit, determined by laser diffraction analyzes; error bars $=$ spreading of 15 repeated measurements

SMC differ slightly and a first estimation is possible. The size distributions show that the SMC-application led in 9 of 10 cases to a minor release than the SSCapplication. The only exception occurred for PU-ZnO. More detailed and robust findings are only possible taking into account the determined spray process parameters and analytical parameters for aerosol conditioning and sampling as shown in the next paragraph.

The $\mathrm{PSD}_{0}$ s determined by the APS were very similar among one another and show only the leftover slope of the total $\mathrm{PSD}_{0}$ in direction to coarser particles. In this context, the representation in Fig. 10 should suffice here. In fact, Fig. 10 shows the transformed $\mathrm{PSD}_{0}$ (for a single analysis), which were correlated to the devicespecific release numbers of EEPS and APS for the purpose of comparison. Despite the different equivalent diameters, it is evident that the APS supplemented well the EEPS size range. This based on the fact that the spray aerosols consist of spherical and compact particles with nearly unit-density. The decrease in the APS-PSD for $x<0.8 \mu \mathrm{m}$ is not an evidence for a bimodal PSD as often misinterpreted in the literature, but a typical artifact of the measuring device that bases on the reduced values in the counting efficiency curve towards the lower detection range limit.
The nanoparticulate fraction $\mathrm{Q}_{0}(100 \mathrm{~nm})$ of the dried spray aerosols based on the EEPS measurement data are shown in Fig. 8. The specified values would be lower taking into account also the coarse fraction of $x>560 \mathrm{~nm}$.

The nanoparticulate fraction of the analyzed coatings and spray units reaches from 10 to 60 no\%. It is evident that the nanoparticulate release depends on the coating system and the application unit. The lowest nanoparticulate fractions arise for the SGA with values between 10 and 20 no\%, whereas the highest ones yielded for the SSCs. The nanoparticulate fraction amounts from 30 to 60 no\% for the application by SSC and SMC. The additivation of the coatings with the TNPAs $\mathrm{Fe}_{2} \mathrm{O}_{3}$ and $\mathrm{SiO}_{2}$ shows no systematic differences to the non-doped reference coatings in the nanoparticulate fraction. Compared with the coating PU, PU-ZnO shows a slight lower nanoparticulate fraction that is attributed to the spray can confection as discussed above.

Specific fractional particle release numbers

Based on the adjusted aerosol-analytical parameters (volumetric flow rates, dilution ratios) and the recorded $\mathrm{PSD}_{0} \mathrm{~s}$ and PNCs (see Fig. 4), fractional release numbers were determined and related to the 


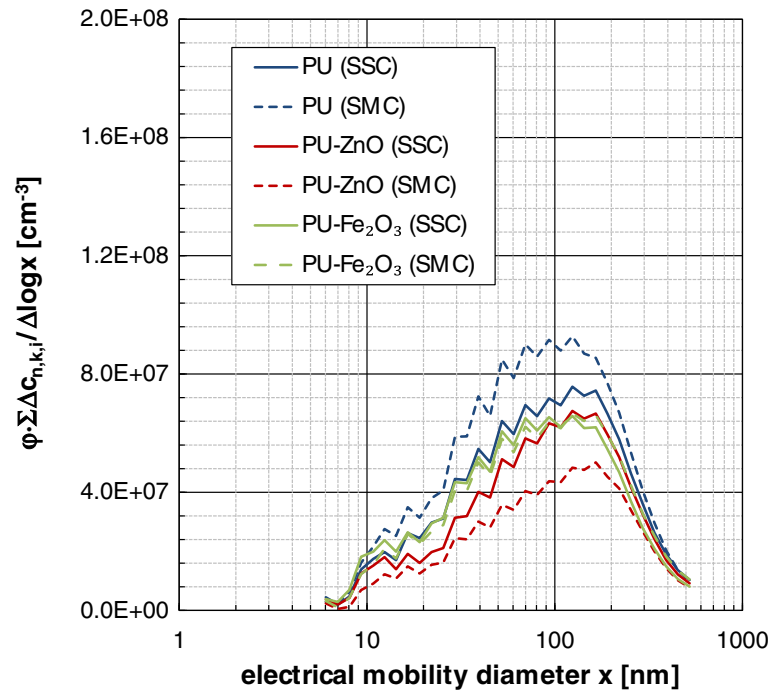

(a) coating system: PU

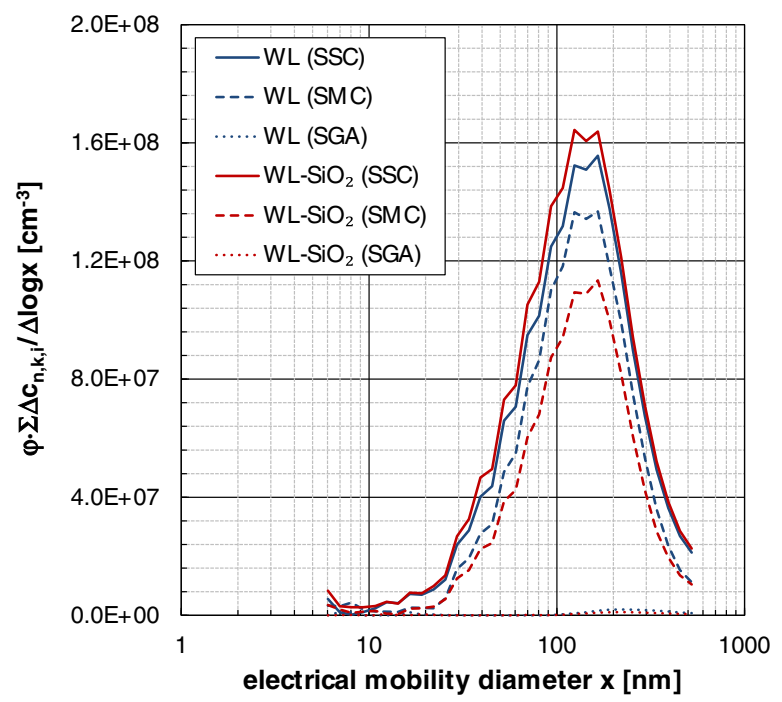

(c) coating system: WL

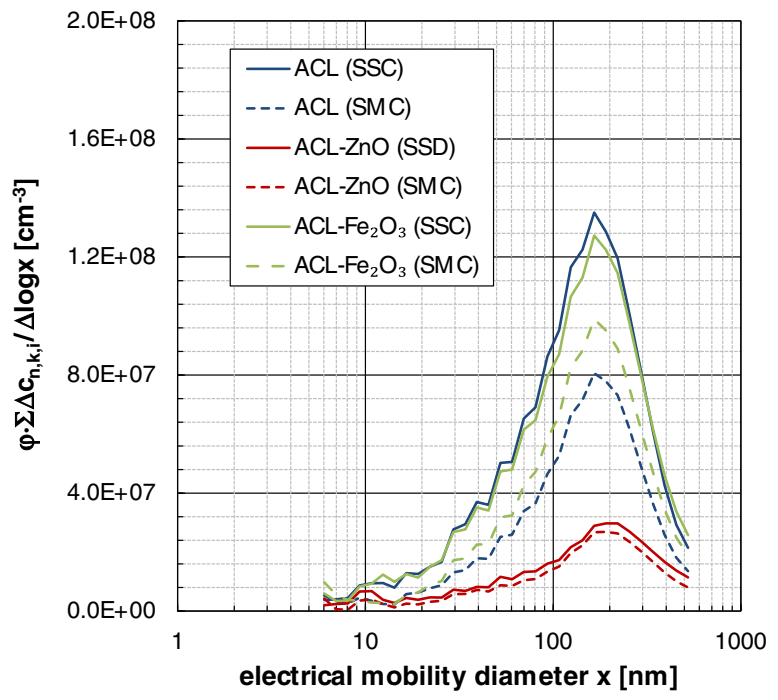

(b) coating system: ACL

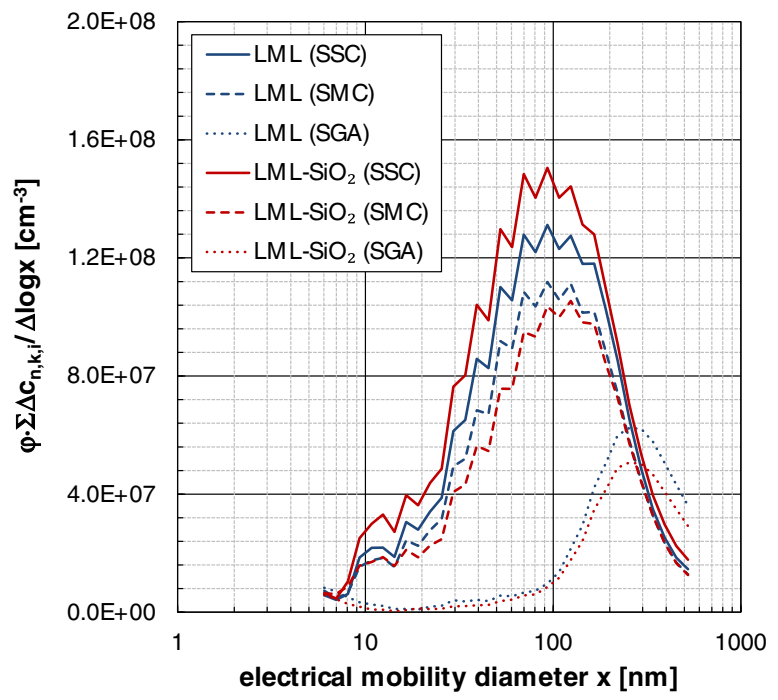

(d) coating system: LML

Fig. 7 Transformed and scaled number weighted particle size distributions determined by EEPS; data based on the first of the 5-12 performed analyses for each configuration

ejection mass of the spray units. For the purpose of comparison within this work or with other release studies, it should be noted that the ejection mass of the spray cans comprises in addition to the solid matter also the propellant and the solvent, whereas the ejection mass of the spray gun consists no propellant content. Using only the solid content, the values of the following release data would be $4-10$ times higher as specified. Furthermore, due to congruent experimental procedures, it is possible to multiply the ejection mass flows given in Fig 5 a with the corresponding values of the specific release numbers of Fig. 9 to obtain the absolute particle flux, which is also known as particle release rate.

Annotations on the evaluated fractions of released particles are given in Table 2, whereas further information can be drawn from the remarks in Göhler et al. (2013). 


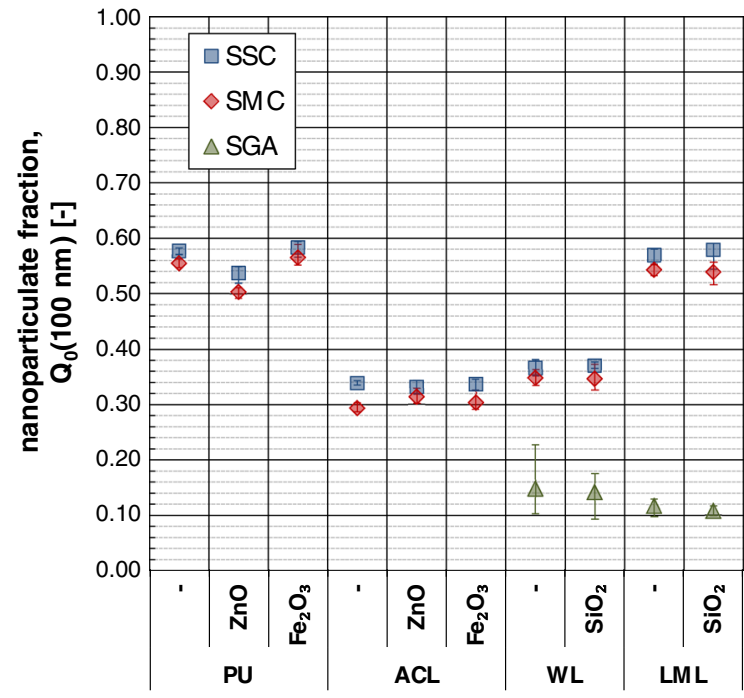

Fig. 8 Nanoparticulate fraction $\mathrm{Q}_{0}(100 \mathrm{~nm})$ based on EEPS measurement data; error bars $=$ data spreading of $5(\mathrm{SGA})$ respectively 6 (SSC, SMC) repeated measurements

Figure 9 shows the determined ejection-mass specific fractional numbers of released particles. It is evident that the particle release numbers depend on the operated spray unit and the used coating system. Regardless the kind of coating and spray unit, the total particle release numbers reach from $5.2 \times 10^{8}$ to $2.7 \times 10^{10} \mathrm{~g}^{-1}$, whereas the micro-particle release numbers lie between $8.7 \times 10^{6}$ and $5.0 \times 10^{8} \mathrm{~g}^{-1}$ and the nanoparticle release numbers extend over $5.3 \times 10^{7} \times 8.0 \times 10^{9} \mathrm{~g}^{-1}$.

Considering only the spray can operation, the SSCs led for all size fractions to higher particle release numbers than the SMCs. The admixture with the TNPAs $\mathrm{Fe}_{2} \mathrm{O}_{3}$ and $\mathrm{SiO}_{2}$ shows no systematic impact on the particle release numbers. The $\mathrm{ZnO}$ doped coatings show partly less particle release numbers as their non-doped counterparts that is attributed to the spray can confection as discussed above.

\section{SEM, TEM and EDX}

Extensive SEM-, TEM- and EDX-analyses on electrostatically deposited spray aerosol particles were performed and led to detailed informations on the species of the dried spray aerosol particles. In the case of dried droplets finer than $200 \mathrm{~nm}$, the matrix sheath became more and more diffuse in the SEM-images, so that the thin matrix sheath around single pigments and also the fine pure matrix material droplets itself were not visible during the SEM-analyses (Model SEM, Model Gemini 982, Karl Zeiss AG, Jena, Germany) at $3 \mathrm{kV}$ acceleration voltage, but could be proofed by the performed TEM-analyses (Model Tecnai 20, FEI Company, Hillsboro, USA).

The schematic illustration in Fig. 10 visualizes the kind of particles recovered for the coating systems containing both $\mathrm{TiO}_{2}$ pigment particles and TNPAs. The coarse particle fraction extends from around $5.0 \mu \mathrm{m}$ down to $0.5 \mu \mathrm{m}$, where the dried matrix droplets showed both embedded pigments and TNPAs. The middle particle fraction reaches from around $500 \mathrm{~nm}$ down to $100 \mathrm{~nm}$. Within this fraction, dried matrix droplets with both pigments and TNPAs, dried matrix droplets either with embedded pigments or with TNPAs and pure matrix particles were identified. The fine particle fraction consisted solely of dried droplets made from matrix material without any pigment particles or TNPAs.

Beside the typical spherical dried droplets, also some large edged particles and a few Si-containing fractal agglomerates without matrix-sheath were observed. The former ones are attributed to fragments of formed thin coating films that were re-entrained from the spray nozzle exits, especially from the SGA. The fractal agglomerates were recovered for nearly all analyzed coating systems, e.g. also for those without deliberately admitted $\mathrm{SiO}_{2}$-TNPAs. The agglomerates showed furthermore a deviant structure in comparison to typically $\mathrm{SiO}_{2}$-TNPA agglomerates. Therefore, it is believed that the observed Si-containing fractal agglomerates may originated rather from incompletely dispersed clusters of other additives or extenders, which were forced open during the spray processes. The true origin of the fractal Si-containing agglomerates could not be fully elucidated within this study. Furthermore, no isolated $\mathrm{ZnO}-$ and $\mathrm{Fe}_{2} \mathrm{O}_{3^{-}}$ TNPAs were observed during the SEM- and the TEM/ EDX-analyses.

Characteristic TEM-images of electrostatically deposited spray aerosol particles are shown in Fig. 11. It is evident that the used TNPAs $\mathrm{ZnO}$ and $\mathrm{Fe}_{2} \mathrm{O}_{3}$ in combination with the manner of the performed precipitation (substrate: carbon-coated TEM grids made of copper, Modell SF162, Plano $\mathrm{GmbH}$, Wetzlar, Germany) are well-suited for their recovery even at lower magnification, whereas the used TNPA $\mathrm{SiO}_{2}$ is less suitable because of the lower material contrast and the concomitance of other Si- 


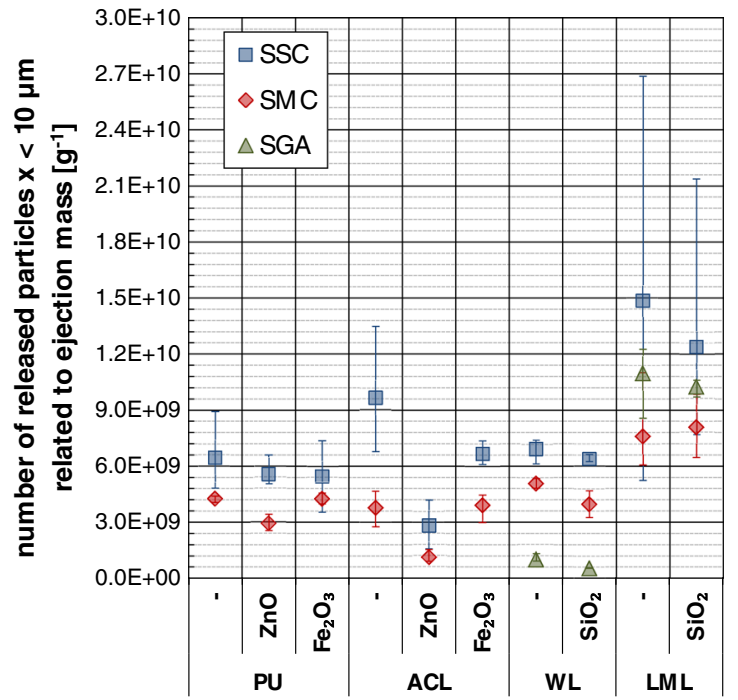

(a) ejection mass specific release number $\mathrm{x}<10 \mu \mathrm{m}$; CPC-data

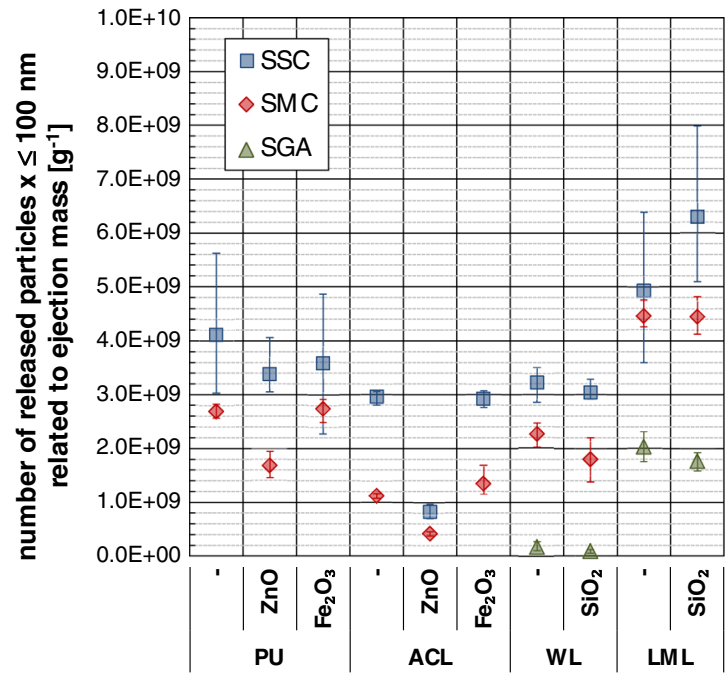

(c) ejection mass specific release number $\mathrm{x} \leq 100 \mathrm{~nm}$; EEPS-data

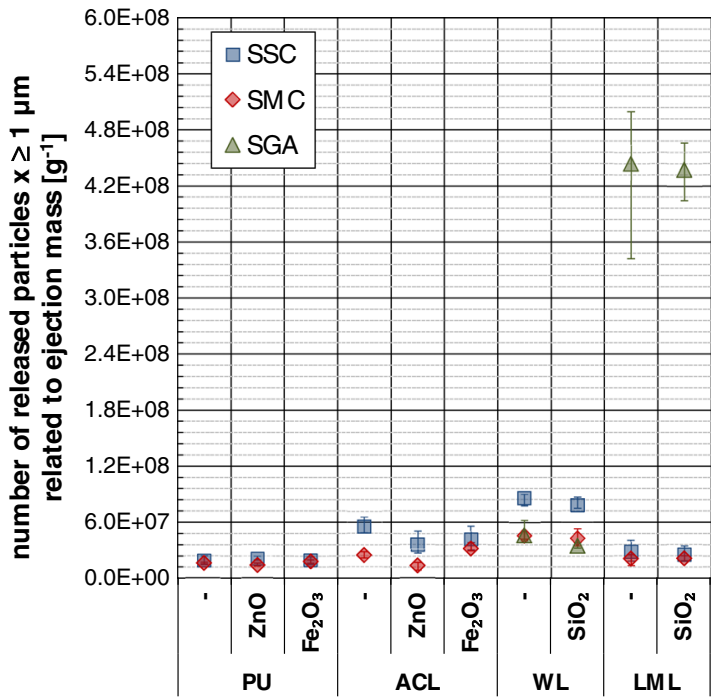

(b) ejection mass specific release number $\mathrm{x} \geq 1 \mu \mathrm{m}$; APS-data

Fig. 9 Ejection mass specific fractional numbers of released particles; error bars $=$ data spreading of 5 (SGA) and 6-12 (SSC, SMC) repeated measurements

containing additives that were typically processed within coatings.

\section{Summary and conclusion}

The airborne (nano)-particle release during spray application of nanoparticle-doped coatings by two kinds of propellant spray cans and a manual gravity spray gun was granulometrically analyzed. Therefore four types of coatings were doped with three kinds of metal-oxide TNPA $\left(\mathrm{ZnO}, \mathrm{Fe}_{2} \mathrm{O}_{3}, \mathrm{SiO}_{2}\right)$. The spray application occurred in a spray-channel, which was integrated in an experimental setup for qualitative and quantitative analyses on dried spray aerosols.

The granulometric results have shown that the spray application led to a particulate release in order of 
Table 2 Annotations on the evaluated fractions of released particles

\begin{tabular}{lll}
\hline $\begin{array}{l}\text { Release } \\
\text { fraction }\end{array}$ & Device & Annotation \\
\hline$x<10 \mu \mathrm{m}$ & CPC & $\begin{array}{l}\text { Total particle release } \\
(6 \mathrm{~nm} \leq x<10 \mu \mathrm{m}) \text {, most robust } \\
\text { results, data based on measured } \\
\text { concentrations below photometric } \\
\text { mode of the device }\end{array}$ \\
& & $\begin{array}{l}\text { Number of released particles in the } \\
\text { micrometre size range } \\
(1 \mu \mathrm{m} \leq x \leq 20 \mu \text { m); data based on }\end{array}$ \\
& APS & $\begin{array}{l}\text { aerodynamic particle diameter } \\
\text { without Stokes correction }\end{array}$ \\
& & $\begin{array}{l}\text { Number of released nanoparticles } \\
\text { (5.6 nm } \leq x \leq 100 \text { nm), data based } \\
\text { on electrical mobility particle } \\
\text { diameter }\end{array}$
\end{tabular}

$5 \times 10^{8}$ to $3 \times 10^{10}$ particles per gram ejection mass, whereof between 10 no\% up to 60 no\% were finer than $100 \mathrm{~nm}$. The represented release data based on worst-case conditions. On the one hand, the total spray jet without obstacle was captured for the analyses, i.e. no plane surface was coated. Thus, the simulated application process is more comparable with spraycoating of e.g. wire-mesh fences or bicycle baskets. On the other hand, optimal measurement conditions were realized for the analyses by preventing particle losses and particle coagulation to freeze the aerosolcondition immediately after the spray-nozzle exit.
To evaluate the more common used PNC from determined release data, defined model rooms were introduced in previous studies (e.g. Göhler et al. 2010, 2013, 2014). In the case of spray application, it is obviously to use the ejected propellant gas volumetric flow $\left(\mathrm{Q}_{\mathrm{PG}} \approx 0.1-0.7 \mathrm{~L} \mathrm{~s}^{-1}\right)$. Doing this, the PNC within the propellant gas cloud would amount values between $5 \times 10^{5}$ and $3 \times 10^{7} \mathrm{~cm}^{-3}$. Similar concentrations were measured for example in $2 \mathrm{~m}$ distance away from a typical cooking emission source (gas stove) due to grilling of $100 \mathrm{~g}$ bacon for $10 \mathrm{~min}$ in laboratory with a room volume of $50 \mathrm{~m}^{3}$ by Manigrasso et al. (2013). However, in the dependence of local airflows, the PNC of the spray clouds would reduce by mixing with air and can thus vary over magnitudes in practice. For example, the spray application of the analyzed acrylate coating (number of released particles $x<10 \mu \mathrm{m}$ related to ejection mass $\approx 1 \times$ $10^{10} \mathrm{~g}^{-1}$; ejection mass flow $1.25 \mathrm{~g} \mathrm{~s}^{-1}$ ) by means of a standard spray can for a duration of $10 \mathrm{~s}$ in a room with a volume of $10 \mathrm{~m}^{3}$ would lead under the premise of ideal mixing/dispersing conditions to a PNC of $1.25 \times 10^{4} \mathrm{~cm}^{-3}$. This value lies within the same order of magnitude as e.g. urban particle number concentrations in offices (e.g. Lonati et al. 2010).

The number weighted $\mathrm{PSD}_{0}$ logged by EEPS showed beside the central peak around $100 \mathrm{~nm}$ also a fine fraction around $10 \mathrm{~nm}$ and below, that could maybe addressed to SOA formation.
Fig. 10 Transformed $\mathrm{PSD}_{0}$ correlated to the devicespecific release number of white-pigmented acrylate coating with $\mathrm{ZnO}$-TNPAs during SMC-application (single analysis no. 455) with schematic illustration of the different kinds of dried spray aerosol droplets observed during SEM- and TEM-analyses

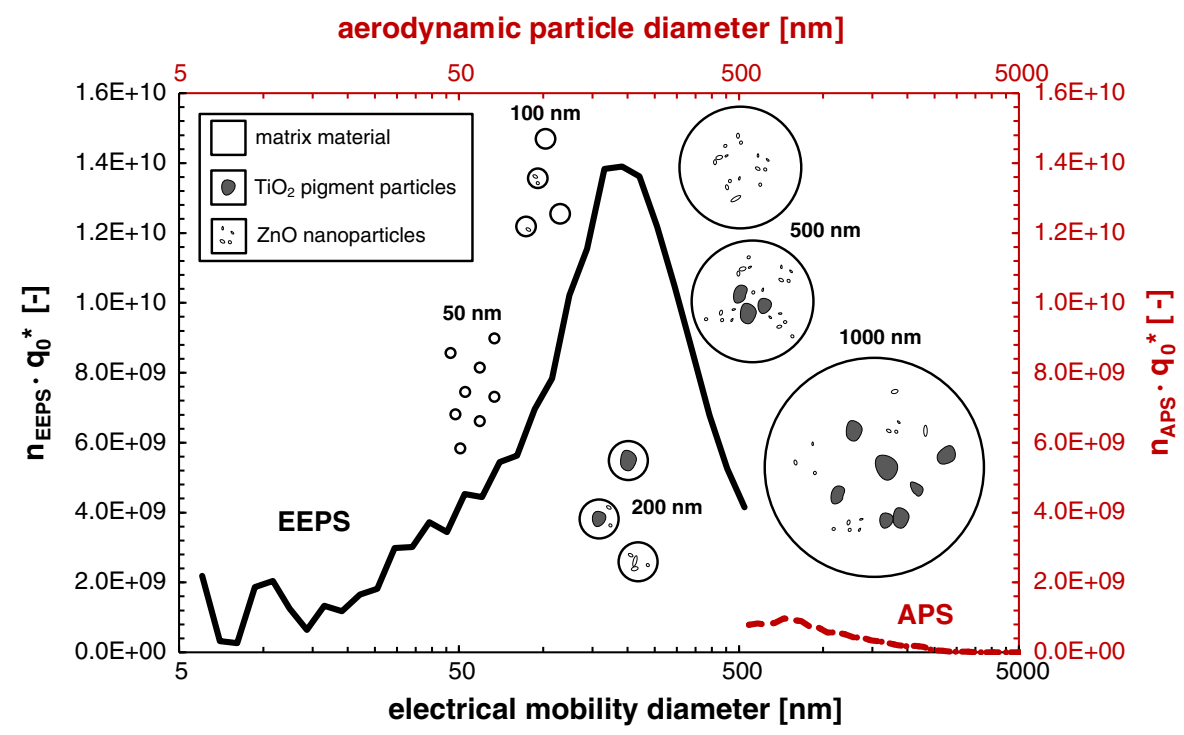




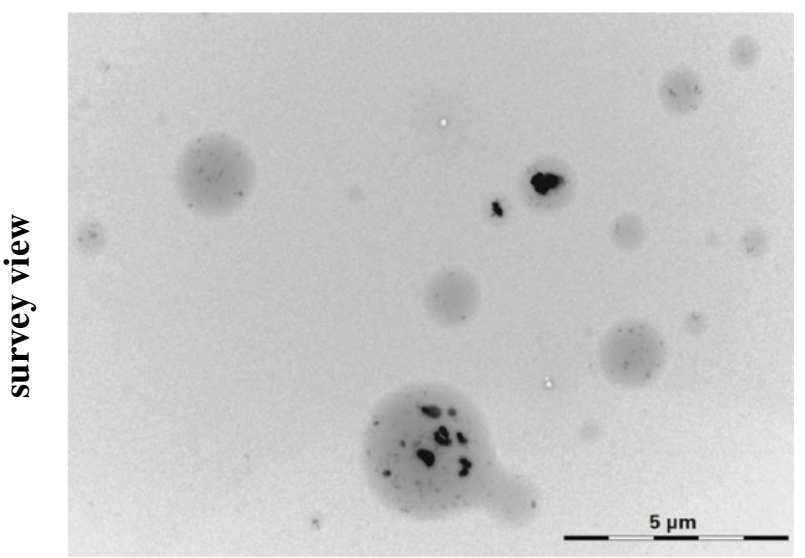

(a) $\mathrm{ACL}-\mathrm{Fe}_{2} \mathrm{O}_{3}$

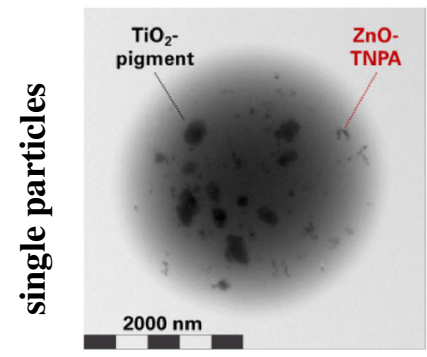

(c) ACL-ZnO

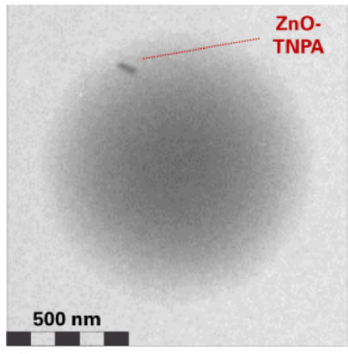

(d) ACL-ZnO

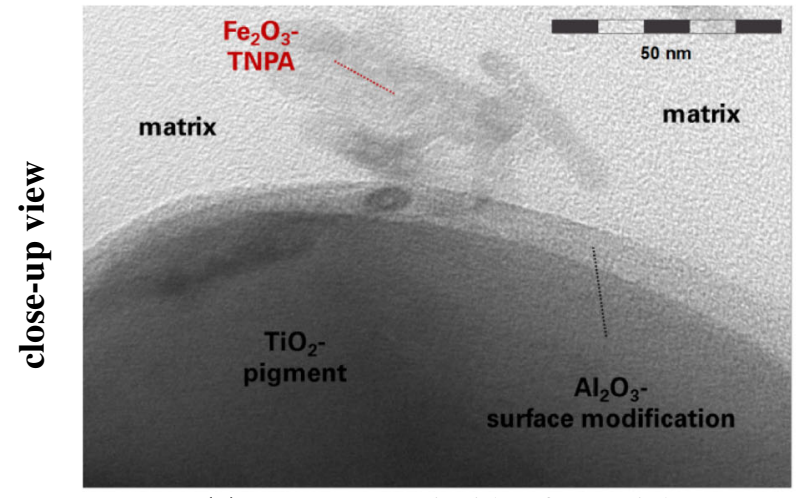

(g) $\mathrm{ACL}-\mathrm{Fe}_{2} \mathrm{O}_{3}$ (inside of a particle)

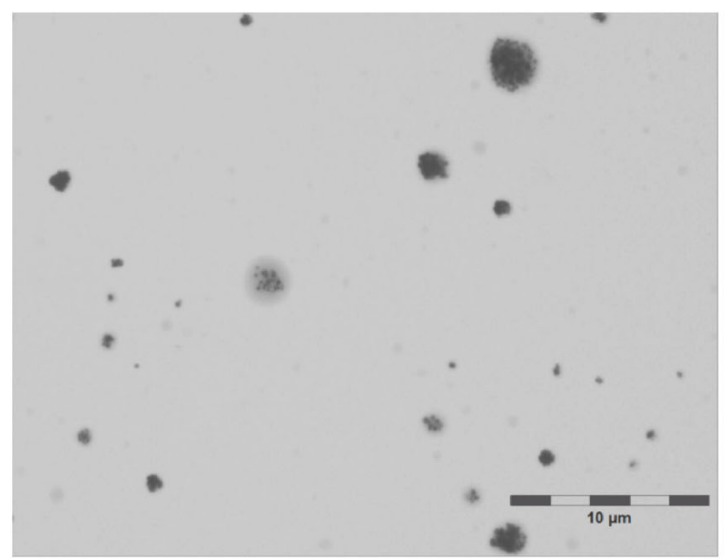

(b) $\mathrm{WL}_{-} \mathrm{SiO}_{2}$

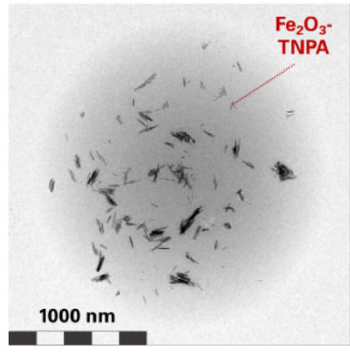

(e) $\mathrm{ACL}-\mathrm{Fe}_{2} \mathrm{O}_{3}$

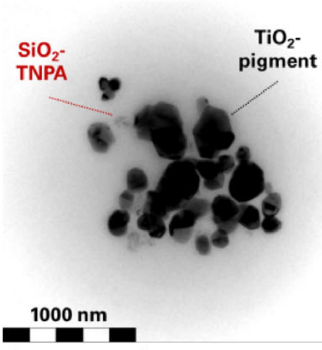

(f) $\mathrm{WL}-\mathrm{SiO}_{2}$

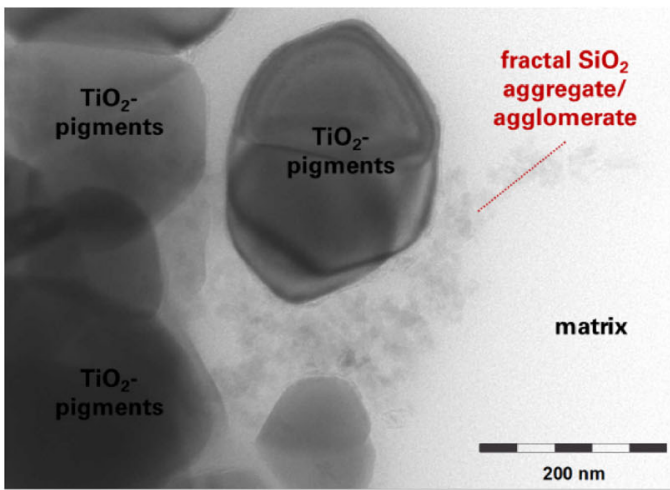

(h) $\mathrm{WL}_{-} \mathrm{SiO}_{2}$ (inside of a particle)

Fig. 11 TEM-images of electrostatically deposited spray aerosol particles

Comparing the nanoparticle-doped coatings with the non-doped ones, the admixture of $0.2 \mathrm{wt} \%$ up to $2.6 \mathrm{wt} \%$ TNPA showed no tracer nanoparticle attributed impact on both the macroscopic spray process characteristics and the particle release numbers.

The SEM- and TEM-analyses proved particles made up solely from matrix material and matrix-sheathed pigments, fillers and TNPAs. Isolated $\mathrm{ZnO}-$ or $\mathrm{Fe}_{2} \mathrm{O}_{3^{-}}$ TNPA could not be observed. Nevertheless, imaging analyses suffer from comparatively low number of analyzed particles. Thus, statistically reliable particle material identification measurement methods are one aim for future work in this field of research.

Based on the findings of this and previous studies, we believe that the quality of the ENO-admixture (dispersing state, surface wetting, surface modification) is an more important fact as considered so far, when discussing about potential ENO release. 
Acknowledgments This work was supported by the German Paint Industry Association (VdL, representing about 180 German companies). The Bayer Technology Services GmbH is to thank for additional TEM- and EDX-Analyses. The authors wish to thank all involved members of the VdL for their support and discussions before, during and after the project.

Open Access This article is distributed under the terms of the Creative Commons Attribution License which permits any use, distribution, and reproduction in any medium, provided the original author(s) and the source are credited.

\section{References}

Biskos G, Reavell K, Collings N (2005) Description and theoretical analysis of a differential mobility spectrometer. Aerosol Sci Technol 39:527-541. doi:10.1080/02786829 1004832

Brosseau LM, Fang CP, Snyder C, Cohen BS (1992) Particle size distribution of automobile paint sprays. Appl Occup Environ Hyg 7:607-612. doi:10.1080/1047322X.1992.1038 8052

Brouwer D (2010) Exposure to manufactured nanoparticles in different workplaces. Toxicology 269:120-127. doi:10.1016/ j.tox.2009.11.017

Carlton GN, Flynn MR (1997) Influence of spray painting parameters on breathing zone particle size distributions. Appl Occup Environ Hyg 12:744-750. doi:10.1080/10473 22X.1997.10387758

Dixkens J, Fissan H (1999) Development of an electrostatic precipitator for off-line particle analysis. Aerosol Sci Technol 30:438-453. doi:10.1080/027868299304480

EN 1451-1: 1998. Plastics piping systems for soil and waste discharge (low and high temperature) within the building structure-Polypropylene (PP)—part 1: specifications for pipes fittings and the system

European Commission (2011) Commission recommendation of 18 October 2011 on the definition of nanomaterial (2011/ 696/EU). Off J Eur Union 54(L275):38-40

FEA European Aerosol Federation (2013) Annual Report 2013

Froggett SJ, Clancy SF, Boverhof DR, Canady RA (2014) A review and perspective of existing research on the release of nanomaterials from solid nanocomposites. Part Fibre Toxicol 11:17. doi:10.1186/1743-8977-11-17

Göhler D, Stintz M, Hillemann L, Vorbau M (2010) Characterization of nanoparticle release from surface coatings by the simulation of a sanding process. Ann Occup Hyg 54: 615-624. doi:10.1093/annhyg/meq053

Göhler D, Nogowski A, Fiala P, Stintz M (2013) Nanoparticle release from nanocomposites due to mechanical treatment at two stages of the life-cycle. J Phys Conf Ser 429:01204. doi:10.1088/1742-6596/429/1/012045

Göhler D, Stintz M, Kutlescha K, Liewald H (2014) Partikelfreisetzung aus Oberflächen. Farbe und Lack 120:60-66
Hagendorfer H, Lorenz C, Kaegi R, Sinnet B, Gehrig R, Goetz NV, Scheringer M, Ludwig C, Ulrich A (2010) Size-fractionated characterization and quantification of nanoparticle release rates from a consumer spray product containing engineered nanoparticles. J Nanopart Res 12:2481-2494. doi:10.1007/s11051-009-9816-6

Helsper C, Mölter W, Haller P (1990) Representative dilution of aerosols by a factor of 10,000. J Aerosol Sci 21:S637S640. doi:10.1016/0021-8502(90)90323-P

ISO 13320:2009. Particle size analysis-laser diffraction methods

ISO/TS 80004-1:2010. Nanotechnologies-Vocabulary-Part 1: Core terms

Koch W, Lödding H, Mölter W, Munzinger F (1988) Verdünnungssystem für die Messung hochkonzentrierter aerosole mit optischen Partikelzählern. Staub Reinhalt Luft 48:341-344

Kuhlbusch TAJ, Asbach C, Fissan H, Göhler D, Stintz M (2011) Nanoparticle exposure at nanotechnology workplaces: a review. Part Fibre Toxicol 8:22. doi:10.1186/1743-8977-822

Lonati G, Ozgen S, Luraghi T, Giugliano M (2010) Particle number concentration at urban microenvironments. Chem Eng Trans 22:137-142. doi:10.3303/CET1022022

Losert S, von Goetz N, Bekker C, Fransman W, Wijnhoven SWP, Delmaar C, Hungerbuhler K, Ulrich A (2014) Human exposure to conventional and nanoparticle-containing sprays-a critical review. Environ Sci Technol 48:5366-5378. doi:10.1021/es5001819

Manigrasso M, Stabile L, Avino P, Buonanno G (2013) Influence of measurement frequency on the evaluation of shortterm dose of sub-micrometric particles during indoor and outdoor generation events. Atmos Environ 67:130-142. doi:10.1016/j.atmosenv.2012.10.059

McMurry PH (2000) The history of condensation nucleus counters. Aerosol Sci Technol 33:297-322. doi:10.1080/ 02786820050121512

NRC (1983) National Research Concil Committee on the Institutional Means for Assessment of Risks to Public Health. Risk Assessment in the Federal Government: managing the process. National Academic Press, Washington ISBN: 978-0309-03349-7

Patent specification DE19636221C2 (1999) Sprühdose. Peter Kwasny GmbH, Gundelsheim

Patent specification US5957341A (1999) Spray can. Peter Kwasny GmbH, Gundelsheim

Sabty-Daily RA, Hinds WC, Froines JR (2005) Size distribution of chromate paint aerosol generated in a bench-scale spray booth. Ann Occup Hyg 49:33-45

Vorbau M, Hillemann L, Stintz M (2009) Method for the characterization of the abrasion induced nanoparticle release into air from surface coatings. J Aerosol Sci 40:209-217. doi:10. 1016/j.jaerosci.2008.10.006

Wilson JC, Liu BY (1980) Aerodynamic particle size measurement by laser-doppler velocimetry. J Aerosol Sci 11: 139-150. doi:10.1016/0021-8502(80)90030-0 